УДК 338.49

DOI: $10.14451 / 1.192 .286$

\title{
ОЦЕНКА ЭФФЕКТИВНОСТИ ЗАТРАТ НА ОХРАНУ ОКРУЖАЮЩЕЙ СРЕДЫ В АРКТИЧЕСКИХ РЕГИОНАХ
}

(c) 2020 Меркулина Ирина Анатольевна

доктор экономических наук, профессор, профессор Департамента логистики и маркетинга Финансовый университет при Правительстве Российской Федерации, Россия, Москва

E-mail: IAMerkulina@fa.ru

Статья подготовлена по результатам научно-исследовательской работы, выполняемой в рамках государственного задания в ФГОБУ ВО «Финансовый университет при Правительстве Российской Федерации» на 2020 год. Приведены подходы к оценке эффективности затрат на охрану окружающей среды в регионах российской Арктики.

Ключевые слова: Арктика, регион, эффективность, затраты, охрана, среда, экология

Границы Арктической зоны определяются в соответствии с действующим российским и международным законодательством и уточняются в зависимости от международно-правовых договоренностей. Например, в 2014 году сухопутные территории российской Арктики были расширены путем присоединения Республики Коми, а 27 июня 2017 года вступил в силу новый указ, дополнивший российскую Арктику тремя районами Карелии.

Состав регионов Арктики регламентирован действующим законодательством о сухопутных территориях [1], [2], а также законодательством, регулирующим вопросы управления развитием Арктики [3].

Отсутствие договорных отношений, определяющих правовой статус Арктики в международном формате, привело к тому, что определение границ осуществляется на основании соглашения Организации Объединенных Наций в сфере морского права, которое было принято в 1982 году. Основополагающим принципом данного документа выступает законодательное закрепление правомерности определения границ континентального шельфа на основе подачи заявки в комиссию ООН и расширения своих территорий на максимальное расстояние в 370,4 км от побережья, что составляет до 200 морских миль, а если дно является неразрывным продолжением материка, то ещё на 150 морских миль (277,8 км).

Каждый из регионов российской Арктики осуществляет затраты на охрану окружающей среды (ОС), к которым относится сумма расходов хозяйствующих субъектов, целевой направленностью которых выступает природоох- ранная деятельность, финансирование которой обеспечивается всеми источниками (рисунок 1).

K деятельности, целевой направленностью которой выступает охрана природы, относятся сбор, очистка, уменьшение, предотвращение или устранение загрязнений и других неправомерных действий по отношению к ОС.

Затраты на охрану ОС увеличивались во всех арктических регионах, кроме Ненецкого автономного округа, где данный показатель снизился на 113 млн. руб.

Наиболее существенное увеличение было зафиксировано в Мурманской области - на 11301 млн. руб.

Далее следует Ямало-Ненецкий автономный округ - 8391 млн. руб, Республика Саха (Якутия) -7597 млн. руб, Республика Коми -4213 млн. руб, Красноярский край -4174 млн. руб.

Совсем незначительное увеличение было установлено в Чукотском автономном округе и Республике Карелия - 14 и 12 млн. руб.

Вместе с тем, затраты на охрану ОС требуют дальнейшего увеличения, они должны быть направлены на повышение экологической безопасности предприятий арктической зоны, работающих в сферах промышленности с высокими показателями загрязнения ОС, снижение уровня отходов производства и потребления, внедрения современных технологий очистки.

Следующим этапом исследования является сравнительный анализ темпов загрязнения с темпами затрат, который рассчитывается отношением доли природоохранных затрат к валовому региональному продукту (рисунок 2).

Рейтинг регионов по темпам загрязнения приведен на рисунке 3. 
140000

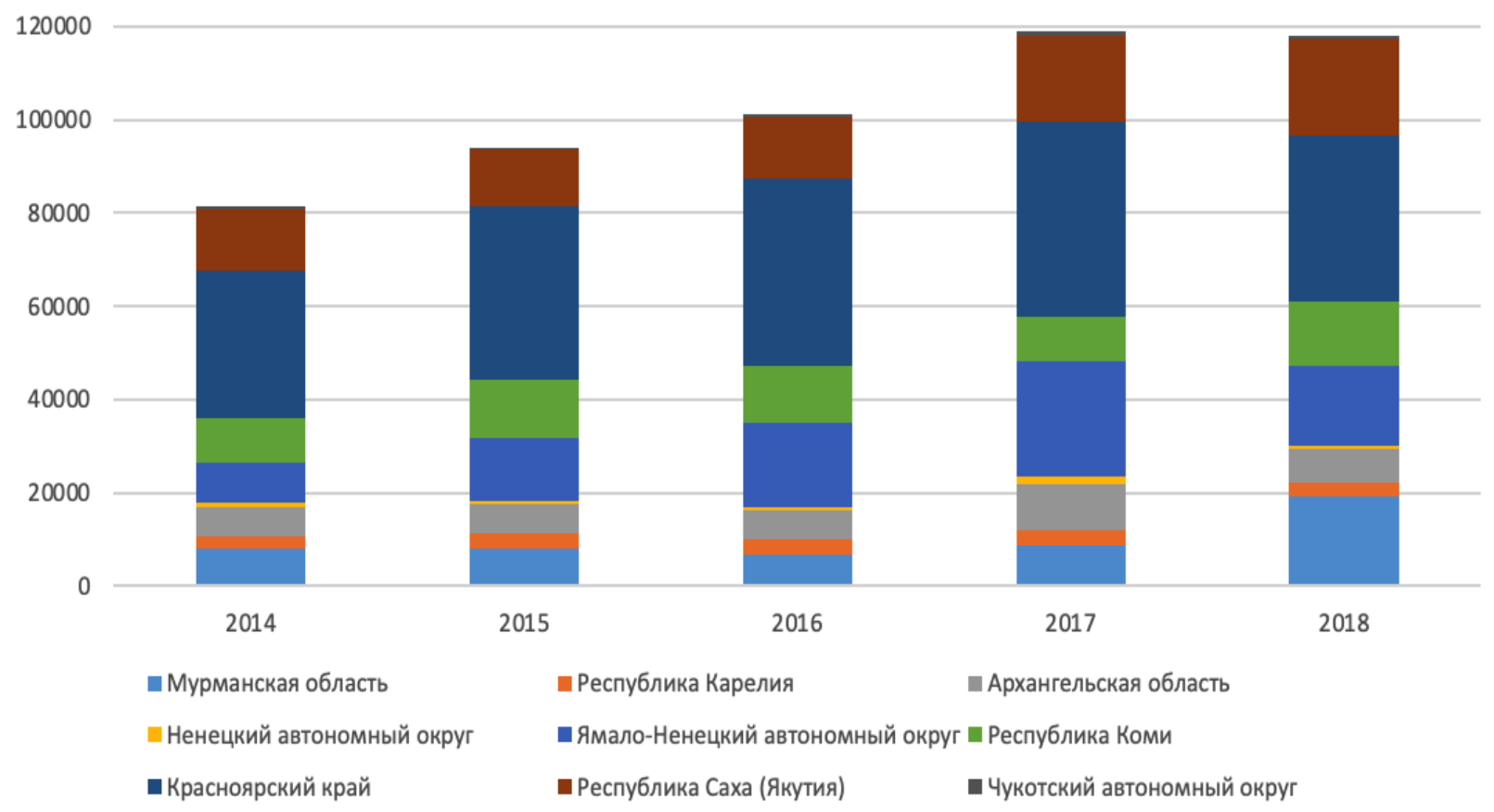

Рисунок 1. Затраты на охрану ОС, млн. руб

Источник: составлено авторами на основании данных [4]

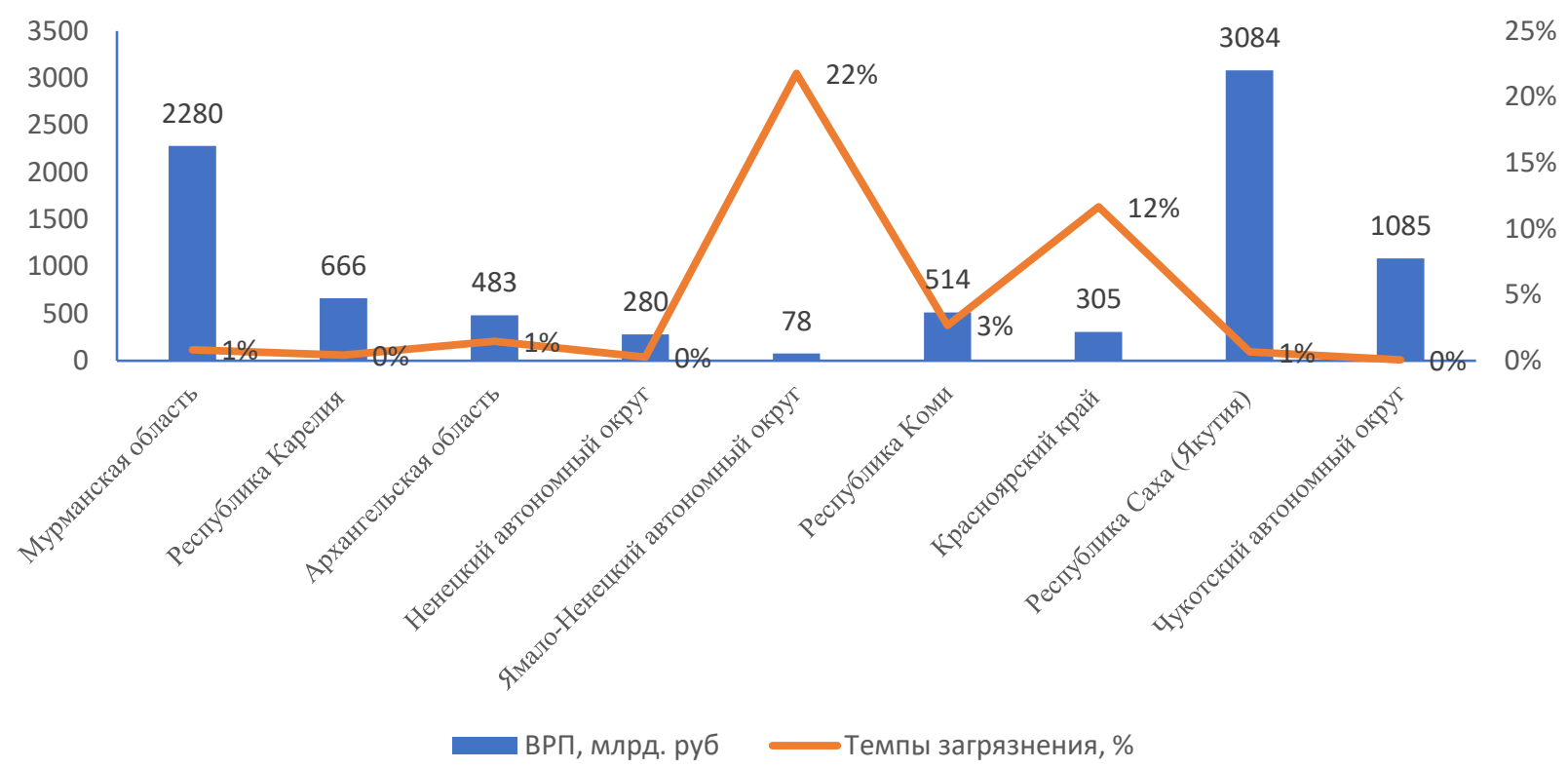

Рисунок 2. ВРП и темпы загрязнения регионов российской Арктики

Источник: составлено авторами 


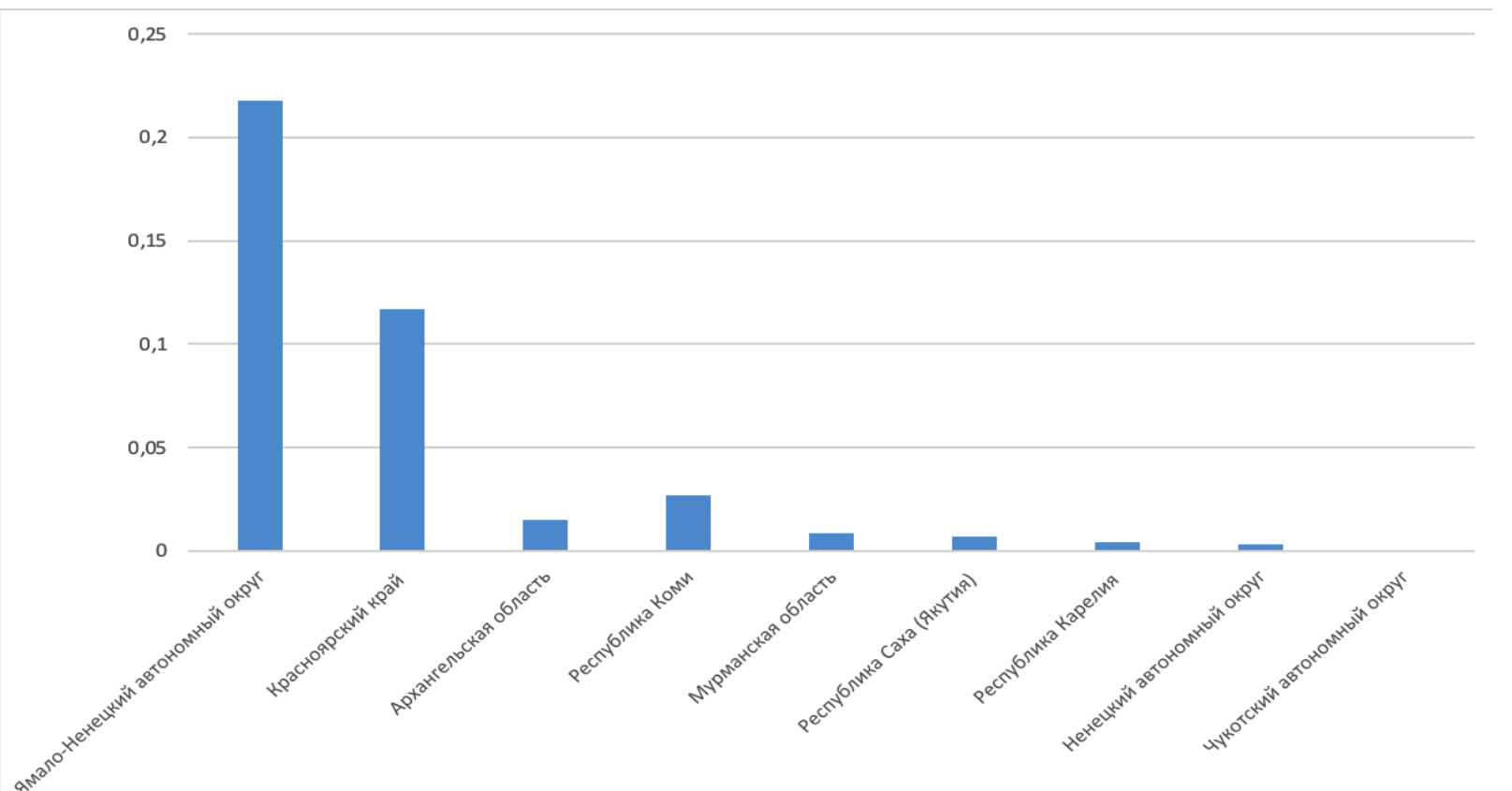

Рисунок 3. Рейтинг регионов по темпам загрязнения Источник: составлено авторами

Объем затрат на охрану ОС в среднем по Российской Федерации составил 715848 млрд. рублей или $0,7 \%$ к ВВП. Таким образом, можно выделить следующие группы регионов:

- регионы, в которых темпы загрязнения выше, чем в среднем по Российской Федерации Ямало-Ненецкий автономный округ, Мурманская область, Архангельская область, Республика Коми, Красноярский край;

- регионы, в которых темпы загрязнения ниже, чем в среднем по Российской Федерации - Республика Карелия, Ненецкий автономный округ, Республика Саха (Якутия), Чукотский автономный округ.

Можно сделать обобщающий вывод по эффективности затрат, который заключается в том, что в ряде регионов, несмотря на значительные затраты на охрану окружающей среды в абсолютном выражении, их относительное значение в сравнении с показателем валового регионального продукта остается незначительным, что свидетельствует об увеличении темпов загрязнения ОС в Арктической зоне. Должна быть создана система стимулирования затрат, где конкретными действующими мерами должны стать налоги и штрафы за загрязнение окружающей среды, акцизные экологические налоги, налогово-амортизационные стратегии, системы кредитования с пониженной процентной ставкой, где целевым назначением кредита могут выступать программы охраны ОС. Инте- ресными инструментами построения экологоориентированного финансирования в зарубежных странах выступают «зеленые» облигации, «зеленое» страхование, привлечение технологий государственно-частного партнерства в сферу охраны окружающей среды.

Следующим показателем для анализа выступает индекс физического объема природоохранных расходов, который представляет собой относительный показатель, характеризующий изменение объема природоохранных расходов в отчетном периоде по сравнению с предыдущим, приведен на рисунке 4.

Индекс физического объема природоохранных расходов снизился в Ненецком автономном округе на 132,8 пп., в Чукотском автономном округе на 56,1 пп., в Ямало-Ненецком автономном округе на 45,4 пп., в Республике Карелия на 25,4 пп., в Красноярском крае на 17,9 пп., в Архангельской области на 10,5 пп. Увеличение было зафиксировано в Республике Коми на 41,8 пп. и в Республике Саха (Якутия) на 5,7 пп.

Следует отметить, что проблемы, связанные с развитием промышленной деятельности на Арктических территориях, следует рассматривать с точки зрения оценки уязвимости территорий, оценки согласия социума на реализацию проектов (власть, бизнес, местные официальные сообщества), оценки региональных ресурсов по всем экосферам, приоритетам развития территорий. 


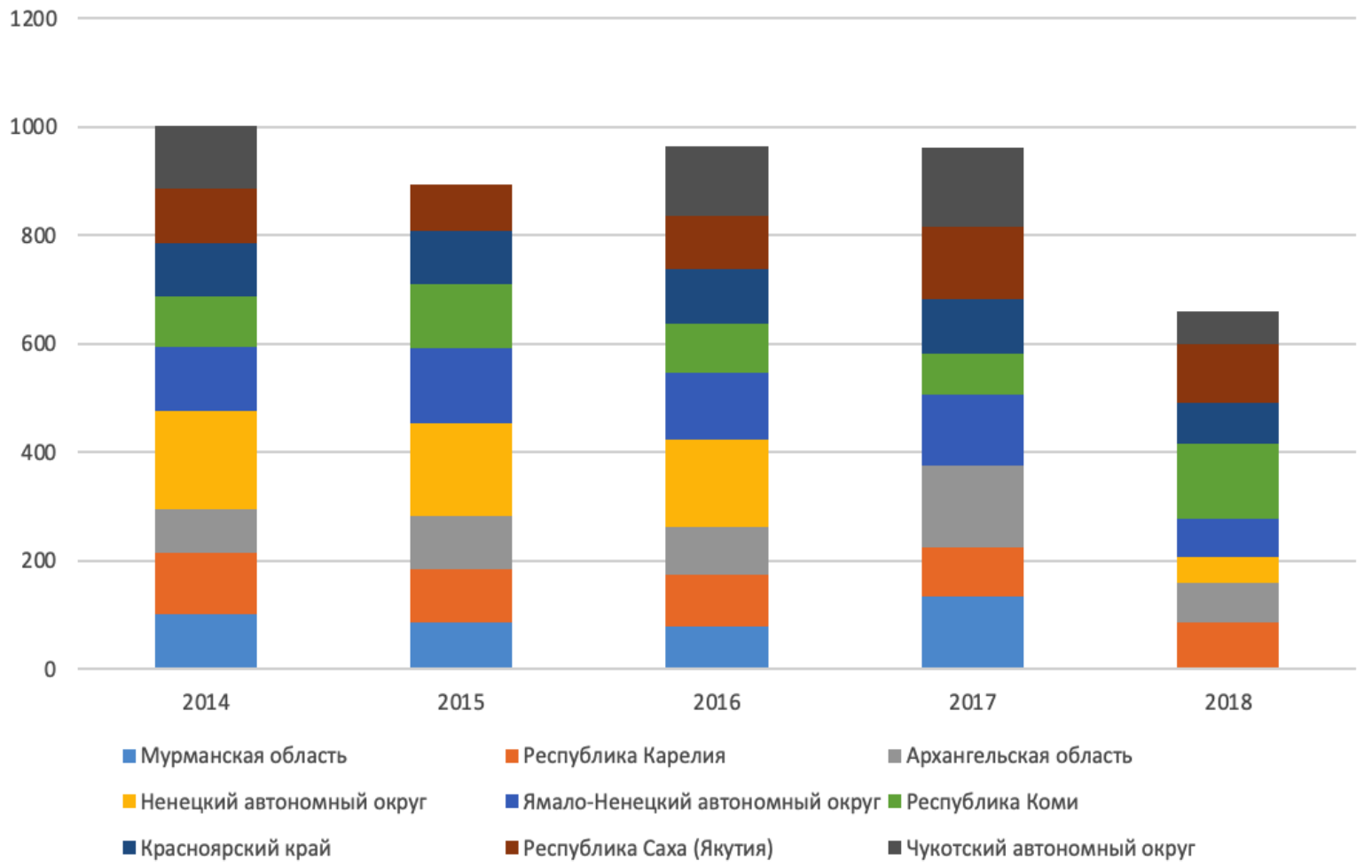

Рисунок 4. Индекс физического объема природоохранных расходов,\% Источник: составлено авторами на основании данных [4]

Таким образом, основными проблемами, связанными с развитием промышленной деятельности на Арктических территориях, являются следующие:

- затраты на охрану ОС требуют дальнейшего увеличения, они должны быть направлены на повышение экологической безопасности предприятий арктической зоны, работающих в сфеpax промышленности с высокими показателями загрязнения окружающей среды, снижение уровня отходов производства и потребления, внедрение современных технологий очистки [5];

- уязвимость экосистем Арктики заключается в том, что требуются значительные усилия для сохранения здоровой экосистемы, происходит истощение минеральных ресурсов, формируется обеднение уникальной флоры и фауны, констатируется наличие аварийных ситуаций в районе Северного морского пути, в местах разработки природных ресурсов на континентальном шельфе, при этом используемые технологические решения в проектах не учитывают всей сложной специфики Арктической зоны;

- в Арктических регионах сосредоточен значительный ранее накопленный экологический ущерб, что необходимо учитывать при реализации горнопромышленных и энергетических проектов;

- климатические изменения несут существенное негативное влияние на реализуемые проекты, что должно быть учтено еще на этапе проработки технического задания проекта;

- зачастую можно констатировать несоответствие параметров проектов требованиям международных соглашений по Арктике.

\section{Библиографический список}

1. Указ Президента РФ от 02.05.2014 № 296 «О сухопутных территориях Арктической зоны Российской Федерации»

2. Указ Президента РФ от 27.06.2017 № 287 «О внесении изменений в Указ Президента Российской Федерации от 02.05.2014 № 296 «О сухопутных территориях Арктической зоны Российской Федерации»»

3. Указ Президента Российской Федерации от 26.02.2019 № 78 «О совершенствовании государственного управления в сфере развития Арктической зоны Российской Федерации»

4. Регионы России. Социально-экономические показатели. 2019: Р32 Стат. сб. / Росстат.- М., 2019.- 1204 с. 
5. Меркулина, И.А. Анализ угроз экологической безопасности для развития промышленной деятельности в Арктике / И.А. Меркулина // Сборник материалов круглого стола «Современный миропорядок и его влияние на национальную безопасность Российской Федерации».- М.: ВАГШ ВС РФ, 2020._611 с. 